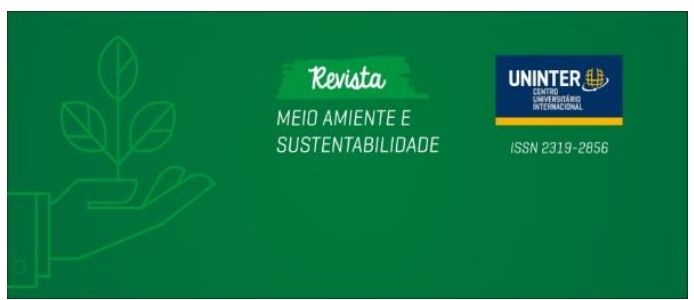

Revista Meio Ambiente e Sustentabilidade

Versão on-line ISSN 2319-2856

Volume 17, número 8. Curitiba - PR. jul/dez - 2019

\title{
Alterações históricas na paisagem entre os rios Canoas e Pelotas, $\mathrm{SC}^{1}$
}

\author{
Gil Karlos Ferri \\ CENSUPEG \\ Bacharel e licenciado em História (UFSC) e \\ mestre em História (UFFS). \\ Rodrigo Berté \\ Pós Doutorando em Educação e Ciências \\ Ambientais - UNED - Universidade Nacional de \\ Ensino à Distância
}

\section{RESUMO}

Ao longo do tempo, a paisagem do município de Celso Ramos foi configurada por fatores naturais e antrópicos. O objetivo deste artigo é analisar o processo histórico da alteração da paisagem neste território, localizado na confluência dos rios Canoas e Pelotas, no planalto do estado de Santa Catarina (Brasil). O município possui vegetações que foram intensamente modificadas pela ocupação humana - por indígenas, caboclos e, sobretudo, colonos de origem italiana. O viés teórico-metodológico deste trabalho foi a História Ambiental, e como fontes utilizamos principalmente a iconografia e as percepções dos moradores locais através da História Oral. A compreensão do uso dos recursos naturais possibilitará reflexões para uma possível preservação ou conservação dos remanescentes da flora, da fauna e dos rios da área em estudo.

Palavras-chave: História Ambiental. Paisagem. Celso Ramos.

\footnotetext{
${ }^{1}$ Este artigo apresenta uma síntese da dissertação de mestrado "Entre rios e florestas: uma história ambiental do município de Celso Ramos, SC”, apresentada pelo autor em 2018 no Programa de Pós-Graduação em História da Universidade Federal da Fronteira Sul, campus Chapecó, sob orientação do professor doutor Claiton Marcio da Silva e coorientação da professora doutora Samira Peruchi Moretto. Disponível em: <https://rd.uffs.edu.br/handle/prefix/2093>. Acesso em: 10 jan. 2019.
} 


\title{
Historical changes in the landscape between the Canoas and Pelotas rivers
}

\author{
Cambios históricos en el paisaje entre los ríos Canoas y Pelotas, estado de \\ Santa Catarina (Brasil)
}

\begin{abstract}
Over time, the landscape of the municipality of Celso Ramos was shaped by natural and anthropic factors. The objective of this work was to analyze the historical and socio-environmental aspects of this territory, located at the confluence of the Canoas and Pelotas rivers, in the plateau of the State of Santa Catarina. The municipality has vegetation that were intensely altered by the human occupation - by natives, Caboclos and, above all, settlers of Italian origin. The methodology applied in this work was Environmental History, and as sources, we used newspapers, maps, legislation, reports, notary offices, photographs. Through Oral History, the memories and perceptions of local residents were observed. Understanding the uses of natural resources will allow reflections for a possible preservation or conservation of the remnants of flora, fauna and rivers in the studied area.
\end{abstract}

Keywords: Environmental History. Landscape. Celso Ramos.

\section{RESUMEN}

A lo largo del tiempo, el paisaje del municipio Celso Ramos ha sido configurado por factores naturales y antrópicos. El objetivo de este artículo es analizar el proceso histórico del cambio en el paisaje de ese territorio, ubicado en la confluencia de los ríos Canoas y Pelotas, en la meseta del Estado de Santa Catarina (Brasil). La vegetación del municipio ha sido intensamente modificada por la ocupación del hombre indígenas, caboclos y, sobre todo, colonos de origen italiana. La orientación teórico-metodológica de este trabajo fue la Historia Ambiental, y las fuentes utilizadas fueron principalmente la iconografía y las percepciones de los moradores de la localidad, procesadas por medio de la Historia Oral. La comprensión del uso de los recursos naturales posibilitará reflexiones dirigidas a una posible preservación o conservación de lo que queda de la flora, de la fauna y de los ríos del área en estudio.

Palabras-clave: Historia Ambiental. Paisaje. Celso Ramos.

\section{INTRODUÇÃO}

"É uma paisagem cicatrizada pelo trabalho humano.

[...] Estradas de terra adernam por essa caótica colcha de retalhos, como se abertas por formigas batedoras." (DEAN, 1996, p. 19).

Warren Dean (1932 - 1994)

Observando a paisagem do município de Celso Ramos, localizado na confluência dos rios Canoas e Pelotas, no planalto de Santa Catarina, podemos observar uma natureza cicatrizada pela ação do tempo e do homem. Para compreender os processos que modificaram esta paisagem, este artigo apresenta uma história que versa sobre os aspectos históricos e socioambientais deste território, através do viés teóricometodológico da História Ambiental. O principal objetivo é analisar as alterações 
antrópicas ocorridas na paisagem do município, observando os impactos deste processo tanto para a sociedade quanto para a fauna, flora e recursos hídricos locais.

Ao longo de milhões de anos, a dinâmica hidrogeológica configurou neste espaço uma mesopotâmia drenada pelos vales dos rios Canoas e Pelotas, favorecendo uma densa concentração de nascentes, lagoas, cursos d'água e cachoeiras. Em sua evolução biogeográfica, a área passou por incontáveis mudanças que resultaram em uma diversidade de seres vivos; faz parte, hoje, do bioma Mata Atlântica. Assim como a maior parte do Planalto Meridional brasileiro, o território de Celso Ramos possuía coberturas vegetais originais que, de acordo com o IBGE, fazem parte da fitofisionomia da Floresta Ombrófila Mista (FOM) e da Floresta Estacional Decidual (FED), com pequenas inserções de campos, devido à proximidade com as estepes presentes na borda oriental do Planalto Sul brasileiro. (IBGE, 2012, p. 80-96).

Nos últimos séculos, sobretudo com a colonização ítalo-brasileira, a ocupação humana alterou significativamente este ambiente. Embora importantes para a economia, processos como a agrocolonização, o extrativismo vegetal e a construção de usinas hidrelétricas causaram impactos socioambientais que precisam ser revisados e problematizados por meio da crítica histórico-ambiental.

\section{OCUPAÇÃO E ALTERAÇÕES ANTRÓPICAS NO AMBIENTE}

O município de Celso Ramos foi criado pela lei n. 7.585, de 26 de abril de 1989, emancipando-se do município de Anita Garibaldi. Localiza-se na região do Planalto Sul de Santa Catarina, e limita-se: ao norte, com o rio Canoas e o município de Campos Novos; ao Sul, com o rio Pelotas e o município de Barracão no estado do Rio Grande do Sul; ao Oeste, com o rio Canoas e o Pelotas, que formam o início do rio Uruguai; e ao Leste, com o município de Anita Garibaldi. De acordo com o IBGE, em 2017 estima-se que a população municipal seja de 2760 pessoas, distribuídas no perímetro urbano e em 15 localidades (mapa 01). (IBGE, 2017). 
Mapa 01 - Mapa municipal de Celso Ramos e suas localidades.

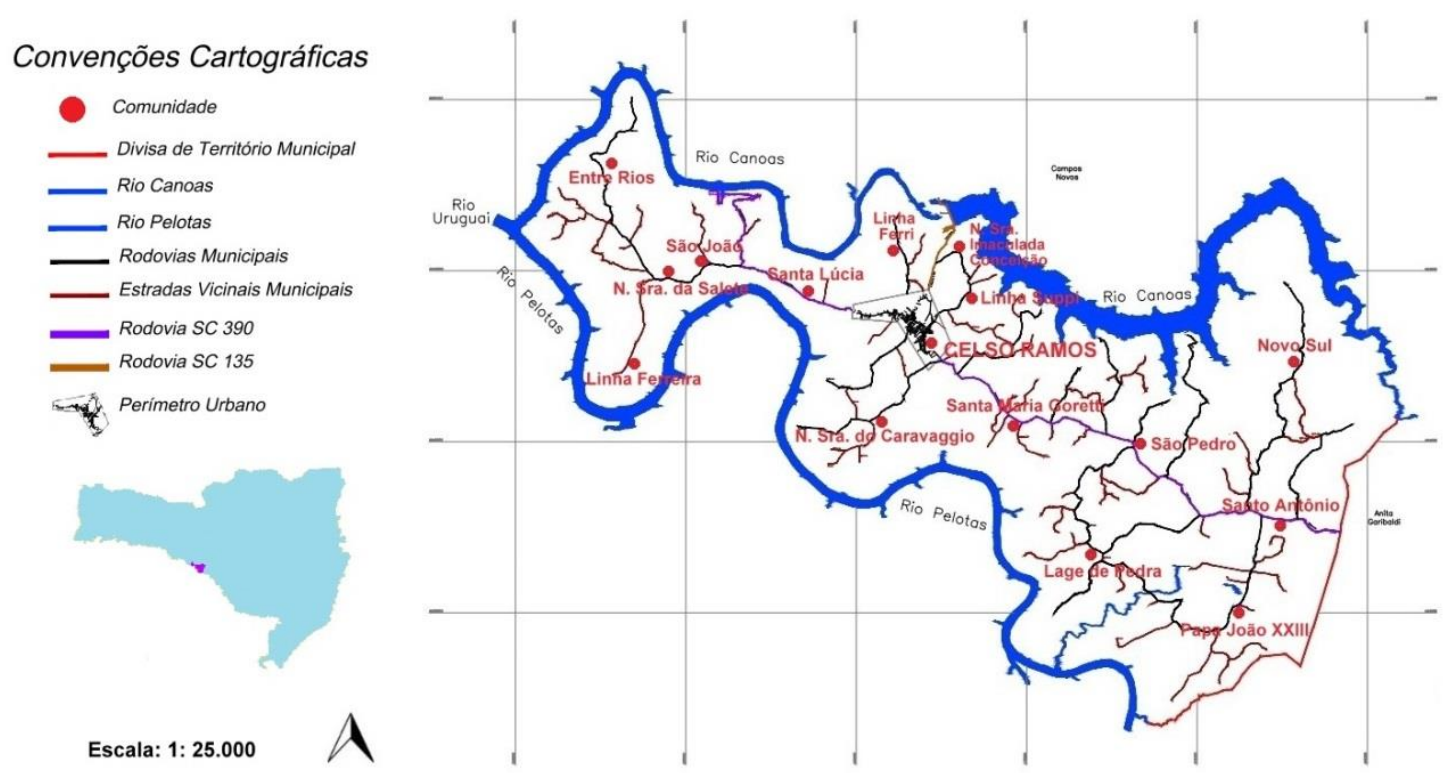

Fonte: FERRI, Gil Karlos; SILVA, Claiton Marcio da; MORETTO, Samira Peruchi. História Ambiental entre os rios Canoas e Pelotas: alterações na paisagem do município de Celso Ramos, SC. In: Anais [...]. Florianópolis, SC: Universidade Federal de Santa Catarina, 08-10 out. 2018.

A ocupação do território que hoje compreende o município de Celso Ramos aconteceu em três fases, com grupos étnico-culturais distintos. A primeira fase vai da PréHistória ao século XIX, quando grupos indígenas ocupavam e faziam incursões pelo território entre os rios Canoas e Pelotas. A segunda fase ocorreu nos séculos XIX e XX, com o estabelecimento de caboclos (luso-brasileiros) que se ocupavam da agricultura de subsistência. A terceira e última fase de ocupação teve início na década de 1930, com a colonização da área por migrantes ítalo-brasileiros que desenvolveram uma intensiva agropecuária e extração vegetal, modificando significativamente a paisagem.

Podemos compreender a paisagem como a materialização da cultura, economia e política, pois ela é repleta de significados identitários e simbólicos, construídos e reproduzidos, que acabam por alimentar o imaginário social. Nas palavras do geógrafo Milton Santos, "a paisagem é o resultado de uma acumulação de tempos”, onde o espaço se altera continuamente para poder acompanhar as transformações da sociedade. (SANTOS, 2004, p. 54). Para Simon Schama, a paisagem é cultura antes de ser natureza, pois projetamos nossa imaginação sobre os elementos físicos. Neste sentido, "uma árvore nunca é apenas uma árvore. [...] Em cada árvore, cada rio, cada pedra, estão depositados séculos de memória”. (SCHAMA, 1996, p. 70). 
Os elementos étnico-culturais indígena, caboclo e ítalo-brasileiro ocuparam e desenvolveram suas atividades utilizando os recursos naturais do território. Embora os indígenas e caboclos praticassem uma agricultura que empregava queimadas como método para a abertura de clareiras na floresta e a adubação do solo, de modo geral, suas reduzidas e esparsas populações não alteraram de modo significativo o ambiente. Mesmo praticando a caça e o extrativismo vegetal, as populações tradicionais mestiças mantiveram um equilíbrio na sua relação com o meio -o que hoje se denomina sustentabilidade. Foi com a agrocolonização ítalo-brasileira, iniciada na década de 1930 com a migração de colonos do Sul de Santa Catarina e do Rio Grande do Sul, que o ambiente local passou a sofrer significativas modificações.

O processo de colonização pode ser observado como uma expansão da fronteira de ocupação pelos colonos, pois se trata de movimentos migratórios e agricultura, e precisa ser problematizado por meio da crítica histórica da relação entre humanos versus humanos e humanos versus meio ambiente. Neste processo, a relação com o ambiente seguiu cada vez mais padrões de exploração capitalista. A vontade dos colonizadores de tornar as áreas de mata agriculturáveis uniu-se ao interesse dos empresários madeireiros, ocasionando a instalação de serrarias na região - principalmente entre as décadas de 1940 e 1980 . A exploração das florestas de araucárias e madeiras de lei representou uma das principais atividades econômicas da região no século XX, favorecendo o crescimento econômico e desencadeando impactos de caráter social e ambiental que justificam uma análise crítica relativa a este local e período. (NODARI, 2016, p. 75-85).

A ocupação das terras entre os rios Canoas e Pelotas pelo colonizador luso-brasileiro foi progressiva. Um dos primeiros impulsos aconteceu na primeira metade do século XIX, com a abertura do caminho das tropas pelo Passo do Pontão - próximo à atual Ponte da Integração, entre Campos Novos (SC) e Barracão (RS). Posteriormente, por ser uma mesopotâmia densamente florestada, diferente dos Campos de Altitude predominantes no entorno de Lages e Campos Novos, ingressaram neste território posseiros, fugitivos e desertores das revoluções rio-grandenses, em especial a dos Farrapos (1835 - 1845) e a Federalista (1893). (QUEIROZ, 1966, p. 16).

Em um artigo de 1897, publicado pelo jornal Região Serrana, a geografia e sociedade do Entre Rios foram descritas nos seguintes termos: 
A vegetação é opulentíssima; o solo de uma fertilidade sem par, produz todos os produtos agrícolas, tanto de serra acima como do litoral, inclusive a mandioca, a cana, e até mesmo o café; a sua população é relativamente densa e notadamente por famílias que nunca vieram à nossa cidade, nem mesmo à sede do seu Distrito de Campo Bello. (FERRI, 2014, p. 39).

Por meio das informações, podemos constatar que o local detém um importante diferencial ambiental em comparação com os campos de Lages, pois se apresenta com solo fértil e clima propício para o cultivo de produtos que exigem temperaturas mais elevadas. O artigo ainda comenta sobre a população que vivia no Entre Rios. Segundo o escrito, a população era relativamente densa e não conhecia Lages, nem tampouco o povoado de Campo Belo, distrito ao qual pertenciam. Exagero ou não, o fato é que o isolamento da região dificultava as comunicações com as vilas e povoados distantes, e mais do que isso, o modo de vida subsistente dos moradores não os obrigava a tais deslocamentos.

Foram realizadas entrevistas com moradores do município de Celso Ramos, que compartilharam suas experiências e opiniões sobre a sociedade e a natureza através da História Oral. ${ }^{2}$ Apesar de riquíssima em informações, a oralidade requer alguns cuidados ao ser utilizada em uma pesquisa histórica. A memória é um processo subjetivo e dinâmico, permeado por ressignificações e jogos de poder, e utiliza-se de instrumentos criados e compartilhados pela sociedade. (MONTYSUMA, 2006, p. 117-125).

O processo de colonização de Celso Ramos foi acompanhado pelo agricultor José Comin, que, ainda criança, migrou para o local em 1934 com sua família. Conforme seus relatos, por meio de herança a região era propriedade de Fausta Soares Rath, que na década de 1930 tratou de vender suas terras. Em 1934, a família Rath firmou acordo com João Comin, para que este noticiasse a disponibilidade de terras para a colonização, mediante o ganho de uma determinada comissão com os negócios. A notícia exaltava a qualidade da terra para a agricultura e a construção, já em andamento, de uma estrada que passaria pela colônia possibilitando a trafegabilidade e o escoamento da produção. João Comin reuniu alguns colonos em Nova Belluno (atual Siderópolis), e deste modo, em julho de 1934, as primeiras famílias partiram do Sul do Estado em direção às terras do Entre Rios, sendo seguidas sucessivamente por outras levas de migrantes. (FERRI, 2014).

\footnotetext{
${ }^{2}$ As entrevistas foram vinculadas ao projeto de pesquisa Memória histórico-geográfica do Planalto e Oeste de Santa Catarina: imagens e oralidades, sob a coordenação do professor Dr. Marlon Brandt. Todas as entrevistas foram gravadas e transcritas na íntegra, com TCLE (Termo de Consentimento Livre e Esclarecido) preenchido e assinado, e os arquivos de áudio e texto foram arquivados na UFFS, campus Chapecó, SC.
} 
A possibilidade de continuarem sendo agricultores motivou os colonos de origem italiana a se estabelecerem em novas terras. Ao chegarem a Celso Ramos, um dos primeiros trabalhos que cada família de migrantes realizava era a derrubada da mata para a construção de sua moradia e o início das plantações. O termo utilizado na época era limpar o terreno, pois a mata nativa era observada como um empecilho ao desenvolvimento da agricultura. Para os colonos, assim como de modo geral para todos os europeus que chegaram à América, a floresta era vista como uma diversidade caótica, que precisava ser eliminada ou dominada. (NODARI, 2010/2012).

Aos poucos a vegetação nativa foi forçada a ceder espaço, a ferro e fogo, às roças, lavouras e construções. Era costume na época registrar em fotografia as construções ocupando o espaço antes dominado pelas florestas. Na figura 01 temos uma imagem com este objetivo, através da qual procurava-se destacar "o progresso da civilização" que o incipiente núcleo urbano de Celso Ramos representava no meio das matas de araucária do planalto catarinense. Devemos levar em conta que as fontes icnográficas não encerram em si o passado, mas contém uma representação deste. As imagens fazem parte de uma construção social que seleciona e omite fatos, favorecendo inúmeras interpretações. Por isso, faz-se necessária uma análise cautelosa da intermediação que a imagem faz entre o passado e o presente. (BURKE, 2004, p. 233).

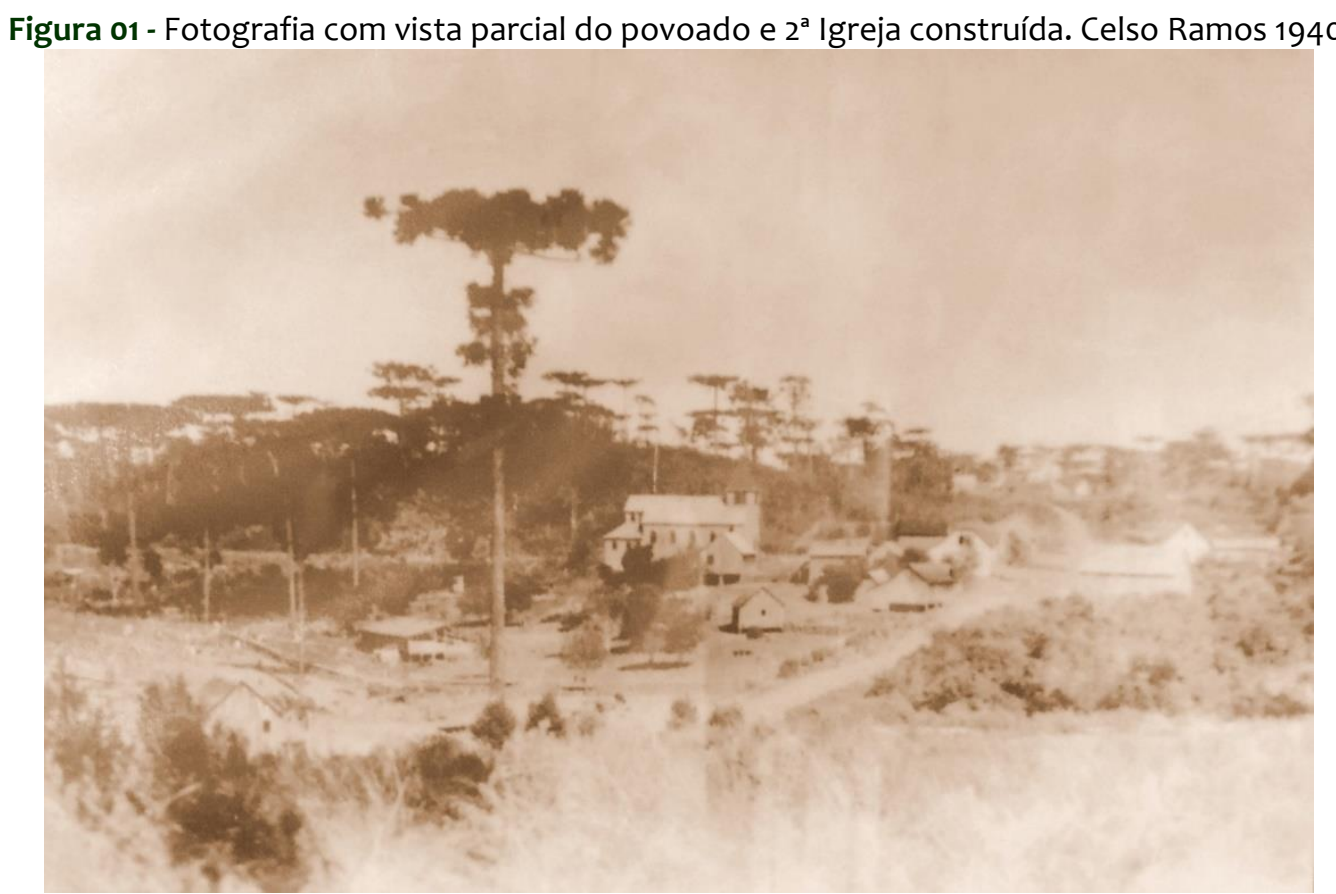

Fonte: Adaptado de (FERRI; SILVA; MORETTO, 2018). 
Para os colonos, a floresta era notada em termos do que não era, ou seja, daquilo que deixava de oferecer permanecendo em seu estado natural, como lavouras e espaços para construções. Como observou o geógrafo Diogo de Carvalho Cabral, “o sentido do mato emergia exatamente do fato de ele possibilitar outras coisas que não ele mesmo". (CABRAL, 2014, p. 82). Na visão do Estado, das empresas e dos agricultores, sempre que possível, as paisagens florestais deveriam ser aproveitadas de modo comercial.

Antes da instalação das serrarias, os moradores derrubavam e queimavam as árvores para preparar a terra para o cultivo agrícola. Objetivando "limpar o terreno", muitos pinhais foram abatidos e deixados apodrecer, pois a madeira ainda não possuía valor atrativo e consequentemente não podia ser aproveitada de modo comercial.

A inauguração da estrada (atual SC-390) possibilitou o tráfego regular de automóveis e caminhões, favorecendo a comunicação e o comércio da área do Entre Rios com as cidades de Lages e Campos Novos, e, a partir destas, alcançavam-se outros centros urbano-industriais do Brasil. Na figura 02 aparecem diversos caminhões, jipes e pick-ups. Provavelmente feita em um dia festivo, a foto servia para demonstrar prestígio que a posse destes veículos representava para seus donos e ainda para dar ideia do progresso que representavam para a região.

Figura 02 - Fotografia de caminhões e veículos estacionados à frente da $3^{\mathrm{a}}$ e atual Igreja Matriz São Paulo Apóstolo. Celso Ramos, SC, década de 1960.

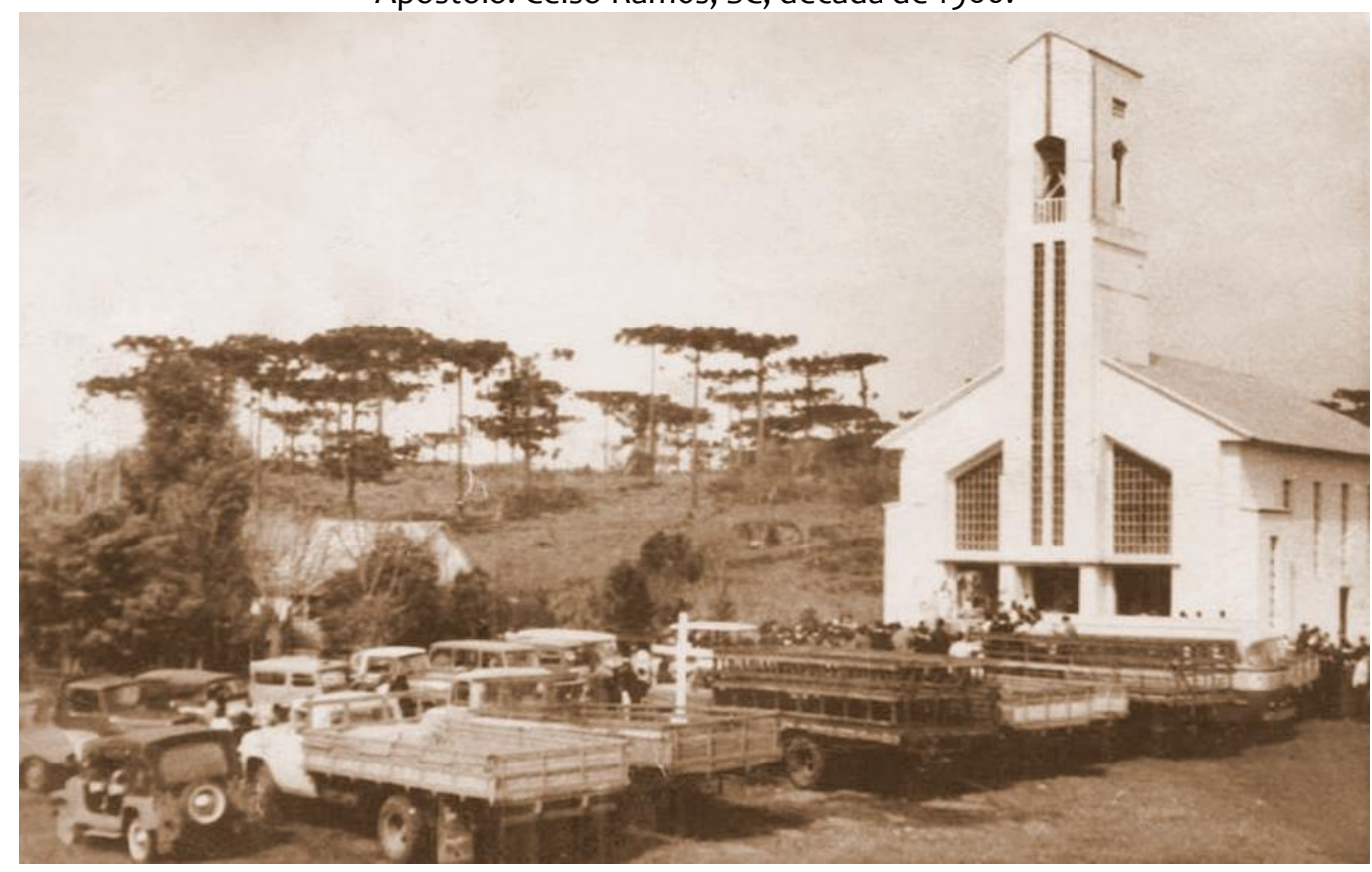

Fonte: Adaptado de (FERRI; SILVA; MORETTO, 2018). 
A partir de 1940, com a construção da estrada que liga Celso Ramos aos demais núcleos urbanos e rodovias do Estado, a região teve um notável crescimento demográfico e econômico, sobretudo puxado pelo setor madeireiro. Acorreram para o local investidores do Rio Grande do Sul - onde os pinhais estavam em processo de exaurimento -, e empresários que já haviam se instalado no planalto catarinense. Percebendo a oportunidade de ganhos econômicos, alguns colonos instalaram serrarias na área, transformando-se em madeireiros.

A densa mata de araucárias foi o principal atrativo para os empresários do setor madeireiro. Além da disponibilidade de matéria-prima, a abertura da estrada estadual e a utilização de tecnologias que permitiam a geração de energia contribuíram para a instalação das serrarias.

Tratando-se de uma indústria, as madeireiras tinham seu funcionamento padronizado, a fim de otimizar o tempo e a produção. Os pinheiros eram derrubados no mato, descascados, arrastados por juntas-de-bois e depois estaleirados para o transporte até a serraria. Com a vinda de tratores e caminhões, sobretudo a partir da década de 1960, este trabalho foi facilitado.

Instalada na área da antiga firma Pandolfo, a Fazenda Lapal, também conhecida como Novo Sul, abrigou uma importante indústria madeireira. A madeireira de propriedade de Laurindo Paese destacou-se por sua organização industrial e grande produção. Durante o tempo em que esteve ativa, a indústria contou com uma vila própria para os funcionários, com casas, escritório, escola, galpões para serraria (figura 16), estábulo e fornos de carvão. (CAMPOS DA MEMÓRIA, 2004). Além da madeireira Novo Sul, diversas serrarias instaladas em localidades do interior de Celso Ramos acabavam aglutinando, no seu entorno, moradias rústicas de empregados. Essas pequenas vilas que se formavam tornavam o interior mais povoado e contribuíam para modificar ainda mais o ambiente no qual se instalavam, tornando-se marcos na paisagem. Atualmente, a fazenda Novo Sul é propriedade da empresa Gaboardi, que realiza a extração de pinus reflorestado.

Além das madeireiras, muitos agricultores realizaram o plantio homogêneo de espécies exóticas, como pinus e eucalipto. Os reflorestamentos geralmente tinham como objetivo ocupar uma área acidentada, pedregosa e não utilizada das propriedades. Em longo prazo, a esperança dos agricultores era conseguir um dinheiro com a venda da madeira. Entretanto, o preço por tonelada comercializada acabou, por vezes, sequer 
pagando os custos com o plantio, cuidados e transporte. Outro problema é que espécies exóticas como o Pinus estão se estabelecendo de modo espontâneo em áreas antes dominadas pela flora nativa. Essa invasão dificulta a recuperação de áreas degradadas, pois as plantas exóticas competem com as espécies nativas.

$\mathrm{Na}$ época, o processo de extrativismo vegetal foi bem visto pelos moradores locais. Para a criação de animais, principalmente gado, os pinhais não tinham valor e eram vistos como um problema, pois, segundo a visão da época, a queda de suas grimpas (folhas) sujava o potreiro. Para a agricultura, as terras com florestas só tinham valor por causa da possibilidade de se derrubar e queimar a mata nativa para adubar o terreno a ser cultivado. Inseridos neste contexto de luta contra a floresta e avanço da civilização, os empresários puderam executar seus negócios de exploração vegetal. Seus lucros custaram a quase extinção das matas de araucárias, sem que fossem vistos como predadores, muito pelo contrário, foram saudados como os promotores do progresso.

Resultado da evolução intrínseca com o ambiente, a fauna da região deste estudo chama a atenção pela grande quantidade e diversidade de animais que a compõem. Desde os primórdios da ocupação humana da área, as caçadas e pescarias representaram fonte de alimento e subprodutos para os indígenas. Para os luso-brasileiros não foi diferente. Porém, com a colonização italiana a caça e a pesca se intensificaram, desequilibrando o ecossistema com a predação de espécies. Nas histórias orais contadas pelos caçadores, a prática da caça aparece como um costume que ultrapassa o medo, conforme as palavras de Olivio Ferri "a escuridão da noite e seus mistérios podem até assustar, mas nunca o suficiente para abandonarmos a nossa tradição de caça" (FERRI, 2013, p. 28).

Além de propiciar alimento, a pesca proporcionava lazer e diversão, unindo familiares e amigos. Dada a grande quantidade e diversidade de peixes em sua ictiofauna, os rios e lajeados da região não sofreram demasiadamente os impactos das pescarias. Porém, a utilização de redes inapropriadas e o desrespeito ao período de reprodução dos peixes, por exemplo, são ações que impactam negativamente no ecossistema dos cursos d'água; mas nada comparado às mudanças hidroambientais causadas pelo represamento dos rios, ocasionado pela construção das usinas hidrelétricas.

Se avaliarmos os ganhos econômicos em curto prazo, a colonização em áreas de florestas atingiu os seus objetivos. As florestas cederam espaço para todo tipo de transformação da paisagem através da ação antrópica, como agricultura, criação de 
animais, cidades e indústrias. Entretanto, devemos reconsiderar este processo sob uma perspectiva que vá além do imediatismo econômico. Na conclusão de um estudo socioambiental acerca das florestas do Sul do Brasil, a historiadora Eunice Nodari apresenta uma pertinente crítica acerca do processo de devastação das florestas:

\footnotetext{
Não foram avaliadas à época as perspectivas para o futuro, levando em consideração a preservação e sustentabilidade. [...] Sempre que os interesses econômicos de uma minoria se sobrepuser aos interesses maiores da sociedade, os reflexos repercutem não somente nos seres humanos, mas em toda a natureza. As florestas acabam sucumbindo, e com elas se vai a sua biodiversidade e se perdem as perspectivas diferenciadas de sustentabilidade. (NODARI; FERRI, 2012, p. 260).
}

Em Celso Ramos ocorreu o mesmo processo replicado por toda a Região Sul. É certo que os colonos de origem italiana contribuíram para a maior alteração da paisagem. Porém, as mudanças causadas na natureza local foram protagonizadas por todos os sujeitos deste território. Somam-se ainda os vinculados a políticas estatais e empreendimentos privados que, mesmo planejando à distância, desencadearam grandes intervenções na paisagem, como obras viárias e hidrelétricas.

Os colonizadores e madeireiros, oriundos do Sul de Santa Catarina e do Norte e Serra do Rio Grande do Sul, duplicaram, nas terras de Celso Ramos, o que eles e seus antepassados já haviam feito nas antigas colônias dos locais de onde provinham: desmataram, desenvolveram a agricultura e repetiram "velhos costumes".

\section{HIDRELÉTRICA CAMPOS NOVOS: IMPACTOS SEM PRECEDENTES}

No rio Canoas, no trecho entre os municípios de Campos Novos e Celso Ramos, diversas empresas se uniram como acionistas do consórcio Campos Novos S.A. (ENERCAN); são elas (com respectivas cotas): CPFL Energia (48,723\%), CBA Alumínios (33,137\%), Votorantim Metais (11,625\%) e CEEE Geração e Transmissão (6,514\%). De acordo com a legislação ambiental brasileira (CONAMA, Lei n. 6.938/81 - Resolução n. 006/87), o processo de instalação de uma obra de geração e transmissão de energia elétrica depende de três tipos obrigatórios de licença: prévia, de instalação e de operação. Após “cumpridas" tais exigências, em 2001 iniciou-se a construção da barragem que seria uma 
das mais altas do mundo, e em 2006/2007 as 3 turbinas entraram em operação e passaram a gerar eletricidade, com potência máxima instalada de 880 MW. (ELETROSUL, 1990b).

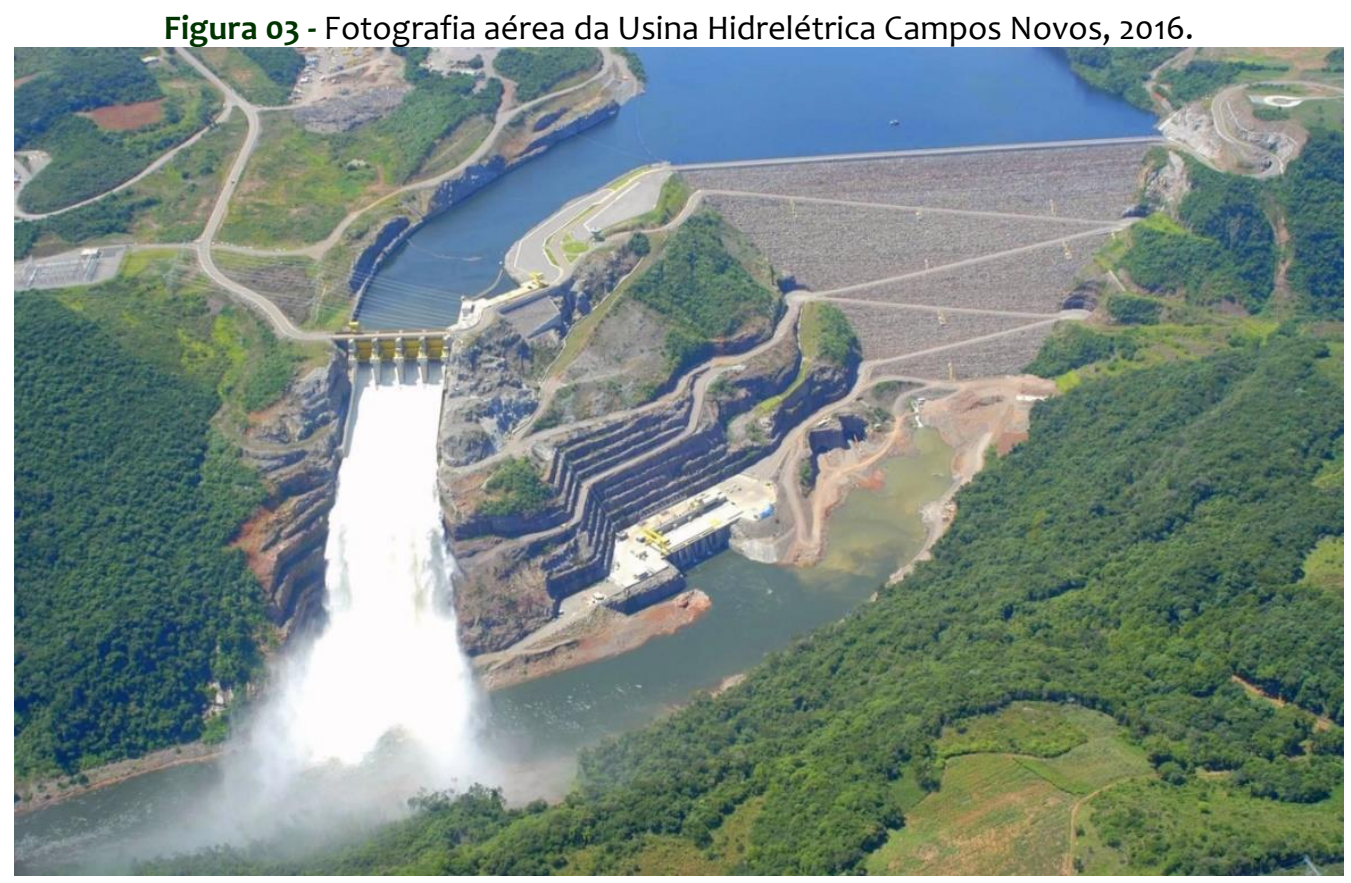

Fonte: Acervo: ENERCAN - Campos Novos Energia S.A. Florianópolis, SC.

Tratando-se de uma obra de grandes proporções e impactos socioambientais, devemos indagar até que ponto as licenças foram de fato cumpridas. Na realidade, existem lacunas nos discursos oficiais sobre tais impactos, certa "retórica dos relatórios", que muitas vezes produziram informações divergentes daquilo que foi vivido de fato pelos atingidos, sejam eles seres humanos ou ambientais (fauna e flora). A formação do lago do reservatório da usina forçou o deslocamento de dezenas de famílias, e tantas outras foram atingidas indiretamente, com partes de suas terras alagadas. Nem sempre houve entendimento nos acordos com a ENERCAN. Se não fosse a organização do Movimento dos Atingidos por Barragens (MAB), a história poderia ter sido mais trágica para as famílias. De qualquer modo, devido à pressão dos atingidos organizados com $O M A B$, as indenizações ou reassentamento foram garantidos aos agricultores afetados. (BLOEMER, 2000, p. 261-273).

No aspecto ambiental, os impactos da UHE Campos Novos foram avassaladores. Quilômetros e quilômetros de floresta nativa das margens do rio Canoas e seus afluentes, sobretudo a Floresta Estacional Decidual, foram sistematicamente derrubados ou apodreceram debaixo d'água com a formação do reservatório da usina. Uma variedade de 
animais silvestres teve seu habitat reduzido, forçando seu deslocamento à procura de novos locais para viver; muitos deles acabaram mortos por "invadir" casas em propriedades e no perímetro urbano das cidades próximas ao lago. Mesmo com as medidas obrigatórias de compensação dos impactos gerados -medidas que, aliás, a empresa supervaloriza como bondade sua para com a natureza-, a biodiversidade local sofreu bruscas mudanças que, por sua rapidez e intensidade, não puderam ser assimiladas pela fauna e flora local.

\section{PERCEPÇÕES E PERSPECTIVAS SOCIOAMBIENTAIS}

Com as intervenções antrópicas, a paisagem natural do município de Celso Ramos passou por uma intensa reconfiguração. Processos como a devastação das florestas, o desequilíbrio da fauna e a apropriação dos recursos hídricos continuam a impactar o meio ambiente, gerando problemas que atingem todos os organismos vivos do ecossistema incluindo-se, notadamente, os seres humanos.

No século XX, o desmatamento para o cultivo agrícola e a criação de animais, que já era realizado pelos indígenas e caboclos, foi intensificado pelos colonos -imbuídos de um ideal capitalista de acumulação de bens e dinheiro. Seguindo uma lógica arcaica, utilizada de Norte a Sul no Brasil, os novos ocupantes mantiveram o sistema indígena de derrubada e queima da floresta para desenvolver sua agricultura, entretanto, o incremento populacional e a pressão sobre o ecossistema tornaram a coivara um sistema insustentável e prejudicial ao ambiente local. O resultado do arroteamento, queimada e destruição das florestas nativas foi a drástica mudança da paisagem da área do atual município de Celso Ramos, tornando-a uma verdadeira "colcha de retalhos", com pequenos e esparsos fragmentos florestais entre áreas ocupadas com construções, pastagens e cultivos agrícolas.

Além da cobertura vegetal e da vida animal, um ecossistema precisa de um solo saudável para manter-se em equilíbrio. O desmatamento, a criação de animais, a agricultura e o uso de agroquímicos são atividades que podem levar à erosão e contaminação do solo. Sendo o solo um recurso finito e não renovável, que leva milhares de anos para tornar-se biofisicamente produtivo, o mau uso pode levar à sua destruição. $\mathrm{O}$ crescimento demográfico, que gera uma crescente demanda pela produção de alimentos, 
tem ocasionado o desmatamento para expansão das áreas agriculturáveis. Entretanto, esse sistema, como observamos no caso de Celso Ramos, é insustentável, pois os solos das florestas representam sistemas muito frágeis, que acabam sendo destruídos com o desmatamento. (TOLEDO et. al., 2000, p. 161 e 162).

Atualmente, o município de Celso Ramos se destaca no cenário estadual pela produção agrícola e pecuária. Entretanto, devemos observar que essa "vocação rural” não parte de uma predestinação natural, mas trata-se de uma opção de ocupação e uso da terra neste território. A contribuição destacada deste município no setor agropecuário e, mais recentemente, hidrelétrico, teve como consequência a substituição em larga escala das florestas nativas por diferentes formas de ocupação do solo. Os resquícios de floresta geralmente capoeiras em diversos níveis de regeneração- constituem as sobras da outrora pujante mata nativa que havia entre os rios Canoas e Pelotas. Esse processo é chamado de fragmentação florestal ${ }^{3}$, e pode ser observado através da imagem de satélite a seguir.

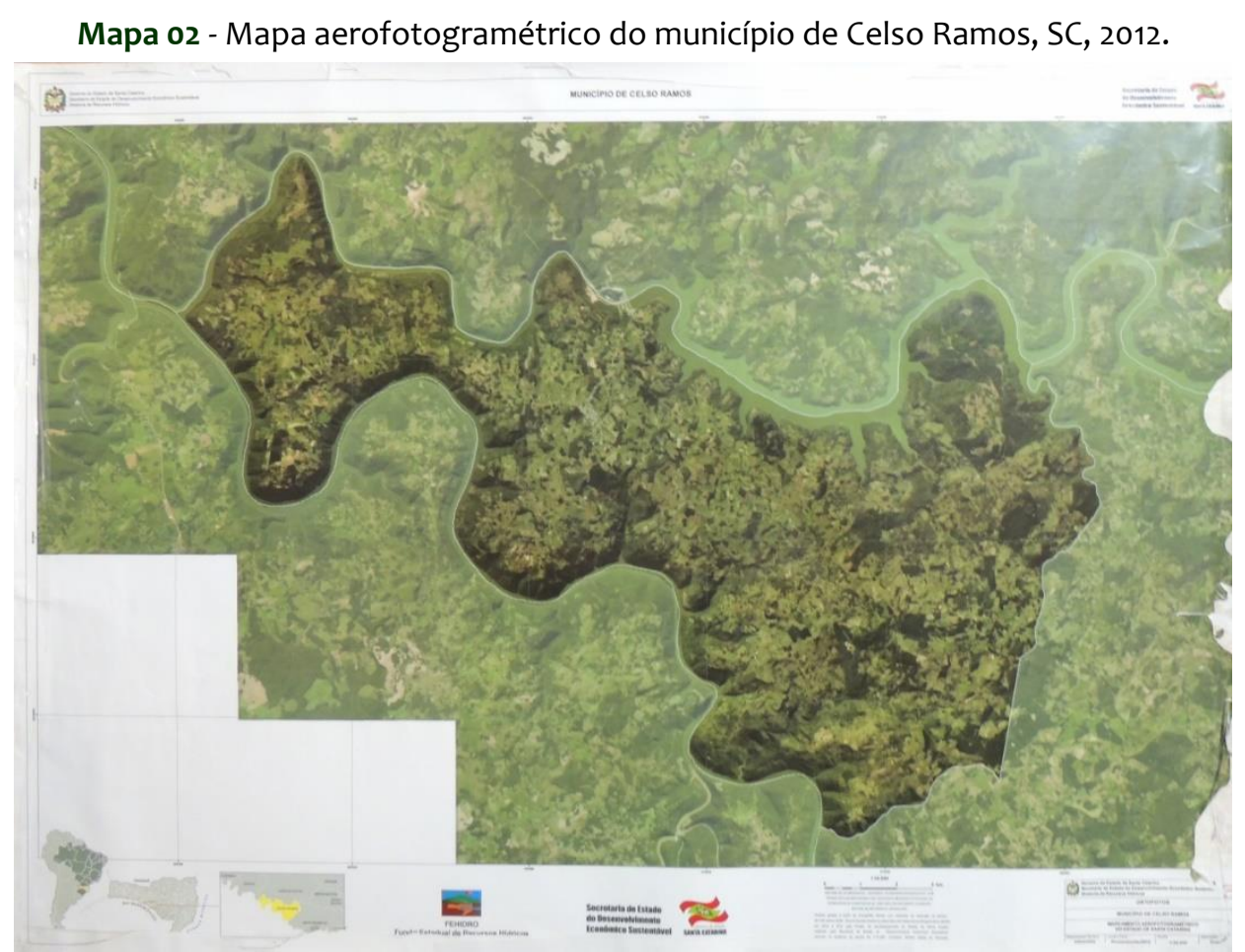

Fonte: Governo do Estado de Santa Catarina. Mapeamento Aerofotogramétrico do Estado de Santa Catarina: Município de Celso Ramos. Governo do Estado de Santa Catarina. Secretaria de Estado do Desenvolvimento Econômico Sustentável. Diretoria de Recursos Hídricos. Florianópolis, SC, 2012. Escala 1: 30.000 .

\footnotetext{
${ }^{3}$ A fragmentação florestal é o resultado da diminuição da cobertura vegetal, em razão de um processo onde formações florestais outrora contínuas são interrompidas por barreiras antrópicas, como estradas, culturas agrícolas, pastagens, reflorestamento de exóticas entre outros, originando fragmentos florestais de diferentes áreas, formas e graus de isolamento. Fonte: VIANA, 1990, p. 113-118.
} 
Embora algumas práticas ainda representem verdadeiros atentados contra o meio ambiente, como as queimadas e o uso indiscriminado de agrotóxicos, o município de Celso Ramos possui especificidades que lhe conferem um alto potencial para tornar-se um local de experimentos sustentáveis. Devido à sua localização entre lagos de usinas hidrelétricas, a biodiversidade de sua fauna e flora e a diminuta população -com baixa densidade urbana e propriedades policultoras espalhadas pelas comunidades rurais- o município apresenta características ideais para o desenvolvimento de projetos de educação ambiental e novas alternativas de renda baseadas na diversidade natural e social deste território.

Figura 04 - Fotografia aérea com vista parcial da cidade. Celso Ramos, SC, 18 mar. 2015.

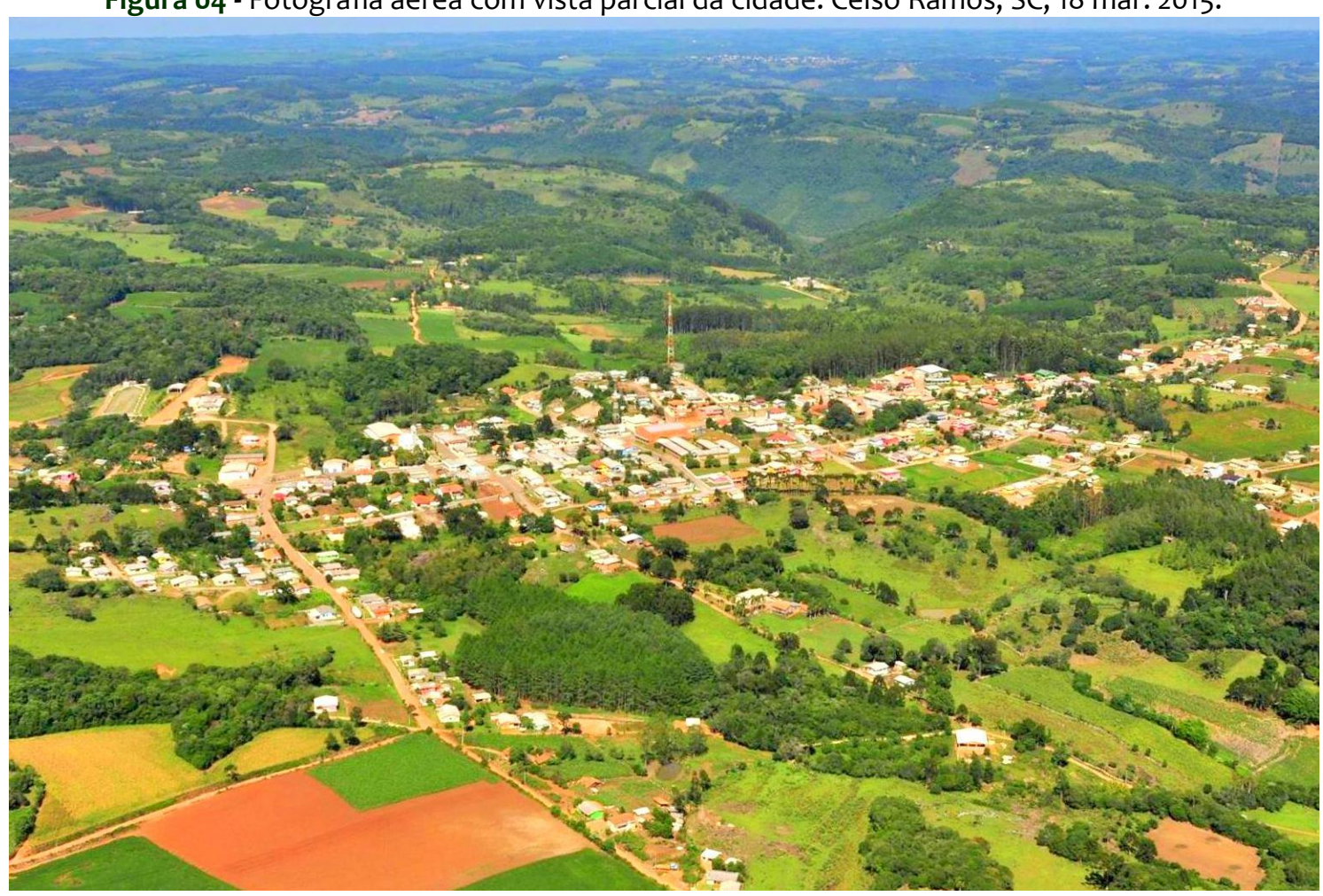

Fonte: Acervo Prefeitura Municipal de Celso Ramos, SC.

Mesmo que ainda não se reconheçam como tal, muitas propriedades desenvolvem cultivos e criação de animais através dos chamados sistemas agroecológicos. O sistema agroecológico é, em resumo, um ecossistema reorganizado para propósitos agrícolas, ou, nas palavras de Donald Worster, “um ecossistema domesticado". (WORSTER, 2003, p. 29). Para Stephen Gliessman, o desafio dos agroecossistemas sustentáveis seria manter as características dos ecossistemas naturais, somando-se a isso a produção de alimentos. Para tornar-se ecologicamente sustentável, um agroecossistema precisa incorporar as qualidades dos ecossistemas naturais, como resiliência, estabilidade, produtividade e 
equilíbrio. (GLIESSMAN, 2000, p. 79). Perante a desleal competitividade econômica das monoculturas e a insustentabilidade de muitos cultivares agrícolas, os sistemas agroecológicos podem representar uma inteligente alternativa para os pequenos produtores rurais.

Através das entrevistas em História Oral, realizadas com moradores do interior do município, pudemos observar suas percepções e perspectivas acerca do ambiente no qual desenvolvem suas vidas. Primeiramente, a noção de mudança transpassa todos os depoimentos. É fato que a paisagem mudou, e eles, os moradores, foram protagonistas destas mudanças. Os "velhos costumes", como as caçadas e o desmatamento, foram apontados como agentes dessa modificação paisagística, além da construção de estradas e, mais recentemente, das barragens. Embora os mais antigos ainda defendam sem constrangimento um posicionamento progressista, notando a evolução tecnológica e a disponibilidade de terras para o cultivo apenas em seus aspectos positivos, há quem perceba essas questões com reservas, considerando também seus aspectos negativos. Como exemplo, a observação dos moradores sobre a alteração do microclima, em decorrência, segundo eles, da construção da UHE Campos Novos, é um indicador de que a percepção do ambiente também passa por mudanças. Apesar da permanência de alguns costumes considerados predatórios ao meio ambiente, a atual situação socioambiental do município apresenta algumas perspectivas sustentáveis para com os remanescentes da flora e da fauna local.

\section{CONCLUSÃO}

De modo voluntário ou implícito, as pesquisas executadas por historiadores ambientais podem contribuir para a conscientização social e para o embasamento de políticas públicas que considerem sociedade e meio ambiente em suas múltiplas interações e reciprocidades.

Já é hora de conhecermos e reconhecermos a importância vital e insubstituível do nosso patrimônio ambiental. Somos os herdeiros do que resta de florestas e recursos naturais. Portanto, devemos proteger essa herança para que ela possa continuar a dar sentido à nossa identidade, essa energia que nos leva a enfrentar os desafios que a dinâmica do tempo e as ações sociais nos colocam à frente. Só assim, com consciência e 
munidos de informações consistentes, conseguiremos ter e deixar para as futuras gerações uma relação mais sustentável com a natureza. Afinal, vida e ambiente são inseparáveis.

\section{REFERÊNCIAS}

AMPLASC - Associação dos Municípios do Planalto Sul de Santa Catarina. Mapa do Território Municipal de Celso Ramos (SC). Campos Novos: AMPLASC, Departamento de Engenharia de Agrimensura, 2016.

BLOEMER, Neusa Maria Sens. Brava gente brasileira: migrantes italianos e caboclos nos Campos de Lages. Florianópolis: Cidade Futura, 2000.

BURKE, Peter. Testemunha ocular: história e imagem. Bauru, SP: EDUSC, 2004.

BRANDT, Marlon. Uma história ambiental dos campos do planalto de Santa Catarina. Tese de Doutorado em História. Universidade Federal de Santa Catarina, Florianópolis, 2012.

CABRAL, Diogo de Carvalho. Na presença da floresta: Mata Atlântica e história colonial. Rio de Janeiro: Geramond, 2014.

CAMPOS da Memória. Inventário do Patrimônio Histórico-Cultural Construído. Salvamento e preservação do patrimônio histórico-cultural e paisagístico da região atingida pela UHE Campos Novos: Abdon Batista, Anita Garibaldi, Campos Novos e Celso Ramos (Santa Catarina). Realização: ENERCAN. Coordenação: ECSA - Engenharia Socioambiental. Execução: UCS - Universidade de Caxias do Sul, IMHC - Instituto Memória Histórica e Cultural, 2004.

COMIN, José. Entrevista concedida a Gil Karlos Ferri. Localidade de Laje de Pedra, Celso Ramos, SC, 26 set. 2017. Acervo do autor.

DEAN, Warren. A ferro e fogo: a história e devastação da Mata Atlântica brasileira. São Paulo: Companhia da Letras, 1996.

GOVERNO DO ESTADO DE SANTA CATARINA. Mapeamento Aerofotogramétrico do Estado de Santa Catarina: Município de Celso Ramos. Governo do Estado de Santa Catarina. Secretaria de Estado do Desenvolvimento Econômico Sustentável. Diretoria de Recursos Hídricos. Florianópolis, SC, 2012.

ELETROSUL - Centrais Elétricas do Sul do Brasil S.A. Usina Hidrelétrica Campos Novos: estudos de controle ambiental e aproveitamento integrado do empreendimento. RIMA Relatório de Impacto Ambiental. Magna Engenharia, 1990b.

ESCOLA de Educação Básica José Cesário Brasil. Celso Ramos: histórias, lendas e contos: construindo a cidadania a partir de suas origens. Celso Ramos: Editora Escala, 2013. 
FERRI, Gil Karlos; SILVA, Claiton Marcio da; MORETTO, Samira Peruchi. História Ambiental entre os rios Canoas e Pelotas: alterações na paisagem do município de Celso Ramos, SC. In: Anais [...] do $5^{\circ}$ Simpósio Internacional de História Ambiental e Migrações. Florianópolis, SC: Universidade Federal de Santa Catarina, p. 08-10 out. 2018.

FERRI, Olivio. Conto: Imaculada Conceição. In: ESCOLA de Educação Básica José Cesário Brasil. Celso Ramos: histórias, lendas e contos: construindo a cidadania a partir de suas origens. Celso Ramos: Editora Escala, 2013. p. 28.

FERRI, Gil Karlos. "Verdes Matas a te Circundar": Aspectos históricos e socioambientais da indústria madeireira em Anita Garibaldi - SC (século xx). 2014. 126 f. TCC (Graduação) - Curso de História, Centro de Filosofia e Ciências Humanas, Universidade Federal de Santa Catarina, Florianópolis, 2014.

FORZZA, Rafaela Campostrini et al. (org.). Catálogo de plantas e fungos do Brasil. Vol II. Rio de Janeiro: Andrea Jakobsson Estúdio; Instituto de Pesquisa Jardim Botânico do Rio de Janeiro, 2010.

FRANCO, José Luiz de Andrade; SILVA, Sandro Dutra e; DRUMMOND, José Augusto; TAVARES, Giovana Galvão (Orgs.). História Ambiental: fronteiras, recursos naturais e conservação da natureza. Rio de Janeiro: Garamond, 2012.

GLIESSMAN, Stephen R. Agroecologia: processos ecológicos em agricultura sustentável. Porto Alegre: Ed. da UFRGS, 2000.

IBGE - Instituto Brasileiro de Geografia de Estatística (Brasil). Administração Federal Brasileira. IBGE divulga as estimativas populacionais dos municípios para 2017. 2017. Disponível em: <https://agenciadenoticias.ibge.gov.br/agencia-sala-de-imprensa/2013agencia-de-noticias/releases/16131-ibge-divulga-as-estimativas-populacionais-dosmunicipios-para-2017>. Acesso em: 10 out. 2017.

IBGE - Instituto Brasileiro de Geografia e Estatística. Manual técnico da vegetação brasileira: sistema fitogeográfico, inventário das formações florestais e campestres, técnicas e manejo de coleções botânicas, procedimentos para mapeamentos. Rio de Janeiro: IBGE, Diretoria de Geociências, 2012.

MONTYSUMA, Marcos Fábio Freire. Um encontro com as fontes em História Oral. Estudos Ibero-Americanos, PUCRS, vol. 32, n. 01, p. 117-125, jun. 2006.

NODARI, Eunice Sueli. Historia de la devastación del Bosque de Araucaria en el sur del Brasil. AREAS - Revista Internacional de Ciencias Sociales, vol. 35, p. 75-85, 2016.

NODARI, Eunice Sueli; FERRI, Gil Karlos. A natureza dominada: ocupação e desmatamento no Rio Grande do Sul e no Oeste de Santa Catarina (1875 - 1970). Relatório final de pesquisa. CNPq - Conselho Nacional de Desenvolvimento Científico e Tecnológico. Florianópolis: Universidade Federal de Santa Catarina, 2012. 
NODARI, Eunice Sueli. As florestas do Sul do Brasil: entre discursos de preservação e ações de devastação. In: FRANCO, José Luiz de Andrade; SILVA, Sandro Dutra e; DRUMMOND, José Augusto; TAVARES, Giovana Galvão (Orgs.). História Ambiental: fronteiras, recursos naturais e conservação da natureza. Rio de Janeiro: Garamond, 2012. p. 260.

NODARI, Eunice Sueli; KLUG, João; MACHADO, Paulo Pinheiro; DIRKSEN, Valberto; KLANOVICZ, Jó. Mosaico de identidades: uma história das práticas socioculturais e econômicas em Campos Novos, Abdon Batista, Anita Garibaldi e Celso Ramos. Realização: ENERCAN. Coordenação: ECSA - Engenharia Socioambiental. Execução: LABIMHA/UFSC, 2004.

QUEIROZ, Maurício Vinhas de. Messianismo e conflito social: a guerra sertaneja do contestado (1912 - 1916). Rio de Janeiro: Civilização Brasileira, 1966.

SANTOS, Milton. Pensando o espaço do homem. $5^{\text {a }}$ ed. São Paulo: Editora da USP, 2004.

SCHAMA, Simon. Paisagem e memória. São Paulo: Companhia das Letras, 1996.

TEIXEIRA, Wilson; TAIOLI, Fabio; TOLEDO, Maria Cristina Motta de; FAIRCHILD, Thomas Rich (Orgs). Decifrando a Terra. São Paulo: Oficina de Textos, 2000.

VIANA, Virgílio Maurício. Biologia e manejo de fragmentos de florestas naturais. In: Anais do Congresso Florestal Brasileiro. Campos do Jordão: SBS/SBEF, 1990.

WORSTER, Donald. Transformações da Terra: para uma perspectiva agroecológica na história. Ambiente \& Sociedade, vol. 05, n. 02, p. 23-44, 2003. 